Некоторые аспекты становления педагогического образования в России
в первой половине XIX в.

Поздняков А.H.

Истринский профессиональный колледж - филиал ГОУ ВО МО «Государственный гуманитарнотехнологический университет»,

Истра, Российская Федерация.

iD ORCID: https://orcid.org/0000-0003-3651-4532, e-mail: alnikpoz@mail.ru

Резюме: Цель статьи - рассмотрение некоторых аспектов становления педагогического образования в России в первой половине XIX века. Автор подчеркивает, что период правления императора Александра I характеризовался масштабной образовательной реформой, целью которой было создание единой разноуровневой системы образования. Ее осуществление потребовало большого количества учителей. Отмечается, что решение задачи подготовки педагогических кадров для гимназий было возложено на университеты. Гимназии в свою очередь должны были готовить учителей для начальных учебных заведений.

В ходе исследования были использованы следующие методы и материалы: анализ документальных источников, оценки по вопросам развития российского образования, опубликованные во второй половине XIX - начале XX вB.

Делается вывод о том, что государственные структуры придавали огромную значимость системе педагогического образования. Предпринимались меры по подготовке преподавателей средних и начальных учебных заведений. Подчеркивается, что важнейшее место начала занимать деятельность, связанная с подготовкой учителей для системы начального народного образования. Сложившаяся система педагогического образования получила свое развитие при Николае І. Ее важнейшим составным элементом стал созданный в Санкт-Петербурге Главный педагогический институт.

Ключевые слова: образовательная реформа, университеты, гимназии, педагогическое образование.

Для цитирования: Поздняков А.Н. Некоторые аспекты становления педагогического образования в России в первой половине XIX в. // Развитие образования. - 2020. - № 3 (9). - C. 8-12. DOI:10.31483/r-86197.

\title{
Some Aspects of Pedagogical Education Establishment in Russia in the First Half of the XIX Century
}

\author{
Aleksandr N. Pozdnyakov \\ Istra Professional College - Branch \\ of SEI of HE of Moscow Region "State University for the Humanities and Technology", \\ Istra, Russian Federation. \\ IDORCID: https://orcid.org/0000-0003-3651-4532, e-mail: alnikpoz@mail.ru
}

\begin{abstract}
The purpose of the article is to review some aspects of pedagogical education establishment in Russia in the first half of the 19th century. The author outlines that the period of the reign of Emperor Alexander I was characterized by a large-scale educational reform, the purpose of which was to create a single multi-level education system. Its implementation required a large number of teachers. It is emphasized that the solution of the problem of training teachers for gymnasiums was entrusted to the universities. Gymnasium, in turn, had to prepare teachers for primary schools.

During the study the following methods and materials were used: analysis of documentary sources, assessments on the development of Russian education, published in the second half of the 19th - early 20th centuries.

It is concluded that state structures attached great importance to the system of pedagogical education. Measures on training teachers for secondary and primary schools were taken. It is pointed out that the most important place has begun to be occupied by activities related to the training of teachers for the primary public education system. The existing system of pedagogical education was developed during the reign of Nicholas I. Its most important component was the Main Pedagogical Institute established in Saint Petersburg.

Keywords: educational reform, universities, gymnasiums, pedagogical education.

For citation: Pozdnyakov A.N. (2020). Some Aspects of Pedagogical Education Establishment in Russia in the First Half of the XIX Century. Razvitie obrazovaniya = Development of education, 3(9), 8-12. (In Russ.) DOI:10.31483/r-86197.
\end{abstract}

\section{XIX е̌ме̌ре̌н пе̌рреме̌ш с̧урринче Рас̧с̧ейре педагогика вёрене̌ве̌ аталаннин хӑш-пӗр аспекчӗ}

Поздняков А.H.

ВМ АВ «Патшалӑх гуманитарипе технологи университече̌» ПВУ фрилиале̌н -

Истра професси колледже̌,

Истра, Рас̧с̧ей Федерацийӗ.

(D) ORCID: https://orcid.org/0000-0003-3651-4532, e-mail: alnikpoz@mail.ru

Аннотаци: Статья те̌ллеве̌ - XIX е̌ме̌ре̌н пе̌рреме̌ш с̧урринче Рас̧с̧ейре педагогика ве̌рене̌ве̌ аталаннин хӑш-пе̌р аспектне пӑхса тухасси. Автор палӑртнӑ тӑрӑх, I Александр император пус̧ пулнӑ тапхӑр ве̌ренӱре масштаб енчен пысӑк реформа иртнипе палӑрса тӑрать. Унӑн те̌ллеве̌ расна шайлӑ пе̌р пе̌тӗм ве̌ренў тытӑме̌ туса хурасси пулнӑ. Ку реформӑна тума йышлӑ учитель кирле̌ пулса тухать. Статьяра палӑртнӑ тӑрӑх, гимназисем валли педагогика кадрӗсене хате̌рлемелли тиве̌с̧е хӑйсем с̧ине университетсем илне̌. Гимназисем вара учительсене пус̧ламӑш ве̌ренӱ заведенийӗсем валли хате̌рлемелле пулнӑ. 
Тӗпчевре с̧акнашкал меслетсемпе тата материалпа усӑ курнӑ: документсене тишкерне̌, XIX е̌ме̌ре̌н пе̌рреме̌ш с̧урринче пичетлесе кӑларнӑ с̧ӑл кус̧е̌сенче Рас̧с̧ей ве̌рене̌вне епле хакланине шута илне̌.

С̧акнашкал пе̌те̌млетӱ тунӑ: патшалӑх тытӑме̌нче педагогика ве̌рене̌ве̌н йе̌ркине пысӑк пелтере̌шле̌х панӑ. Вӑтам тата пус̧ламӑш ве̌ренӱ заведенийе̌сем валли преподавательсем хате̌рлес ене̌пе ку е вӑл йышӑну тунӑ. Автор ак ме̌н палӑртать: халӑх шкуле̌н пус̧ламӑш сыпӑке̌ валли учительсем хатӗрлес пирки тимлӗх вӑйланнӑс̧емӗн вӑйланса пынӑ. Педагогика ве̌рене̌ве̌н йе̌ркеленсе с̧итне̌ тытӑме̌ I Николай патша вӑхӑте̌нче тата малалла аталаннӑ. Ве̌ренӱ тытӑме̌н пите̌ пе̌лтере̌шле̌ пайе̌ Санкт-Петербургра ус̧нӑ Педагогика те̌п институче̌ пулса тӑнӑ.

Тӗп сӑмахсем: ве̌ренӱ реформи, университетсем, гимназисем, педагогика ве̌рене̌ве̌.

Цитатӑлама: Поздняков А.Н. XIX е̌ме̌ре̌н пе̌рреме̌ш с̧урринче Рас̧с̧ейре педагогика ве̌рене̌ве̌ аталаннин хӑшпе̌р аспекче̌ // Вӗренў аталанӑвӗ. - 2020. - № 3 (9). - C. 8-12. DOI:10.31483/r-86197.

\section{Введение}

Вступление России в XIX в. было ознаменовано восхождением на престол императора Александра I. Для начала его царствования были характерны широкие заявления, сопровождавшиеся конкретными действиями по осуществлению реформ в различных областях государственного управления. Император был убежден, что успешная реализация задуманного во многом зависела от развития народного образования. Важным свидетельством этого являлось то, что среди восьми министерств, созданных в 1802 г., находилось и Министерство народного просвещения.

\section{Методы исследования}

В статье предпринимается попытка, остановившись на некоторых аспектах становления педагогического образования, выявить уровень сформированности в России исследуемого периода понимания значимости решения кадрового вопроса для создания и развития образовательной системы. Указанная проблема рассматривается не только через анализ документальных источников, но и через призму оценок, дававшихся авторами работ по вопросам развития российского образования, опубликованных во второй половине XIX начале XX вв.

\section{Теоретическая база исследования}

Твердое убеждение Александра I в необходимости создания в России современной образовательной системы, безусловно, имело свои предпосылки. В вышедшем в 1870-е гг. труде преподавателя Петербургского университета И.А. Галактионова, посвященном жизнедеятельности императора, отмечалось, что «окруженный умными и просвещенными друзьями, Александр не мог не сочувствовать просвещению, которое всегда тесно связано с нравственным и материальным возвышением народа» [2, с. 40].

Стратегическим документом, который определил направления реформирования образования, стали «Предварительные правила народного просвещения». Они были утверждены указом императора от 24 января 1803 г. [5]. В книге кандидата богословия, учителя словесности И.А. Алешинцева, подчеркивалось, что документ был первым в России законодательным актом, «обнимавшим собою все ступени от начального образования до высшего и намечавшим однообразную и общую для всего государства систему школ» [1, с. 19].

Одновременно вышел указ об учреждении учебных округов [9]. На территории страны их было сформировано шесть. В каждом из них создавалась система образовательных учреждений, центром которой ста- новился действовавший или планировавшийся к открытию университет. Проектируемая в округе система образования должна была строится в соответствии со специально разработанной нормативной базой, в основе которой лежал утвержденный 5 ноября 1804 г. Александром I «Устав учебных заведений, подведомых университетам» [12]. Он требовал, чтобы в каждом губернском городе была создана по меньшей мере одна гимназия. Если были «способы к содержанию таковых заведений», то их могло быть открыто и больше. Следующим уровнем образовательных учреждений должны были стать уездные училища. Их следовало открыть не менее чем по одному в губернских и уездных городах. И завершающий, самый многочисленный уровень составляли приходские училища.

Для создаваемой в стране широкой сети учебных заведений требовалось большое количество учителей. Решение этой проблемы предполагало формирование специальной системы педагогического образования. Ключевым ее звеном становились университеты, в связи с чем в их структуре создавались педагогические институты. Историк образования и педагог Г.К. Шмид отмечал: «Эта учебная реформа, которую можно назвать исполинским шагом вперед, конечно, не могла быть проведена без содействия учительских (курсив автора - А.П.) институтов. Самым естественным подспорьем, прежде всего, служили тут университеты...» $[13$, с. 55$]$.

В Петербурге открытие университета в силу различных причин откладывалось. Это могло неблагоприятно сказаться на подготовке учителей для учебных заведений округа, центром которого он являлся. Решение данной проблемы привело к восстановлению в 1803 г. существовавшей еще при Екатерине II, а затем пришедшей в упадок «учительской гимназии». В 1804 г. она была преобразована в Педагогический институт, который должен был стать составной частью будущего Санкт-Петербургского университета [7].

Главной задачей педагогических институтов при университетах была подготовка учителей для гимназий. Те в свою очередь должны были готовить учителей «низших училищ». В «Уставе учебных заведений, подведомых университетам» было зафиксировано, что «в гимназии, сверх обыкновенного преподавания наук, приготовляются к учительской деятельности желающие быть учителями в уездных, приходских и других училищах» [12, с. 627]. Таким образом, складывающаяся система педагогического образования включала в себя два уровня: университетский, на котором через существовавшие в них педагогические институты осуществлялась подготовка главным образом учителей 
гимназий, и гимназический, задача которого состояла в подготовке учителей начальных учебных заведений.

Основная задача Петербургского педагогического института так же состояла в подготовке учителей гимназий, однако качество их подготовки здесь, как ни странно, оказалось более низкого уровня, чем в педагогических институтах при университетах. Дело в том, что на обучение в педагогические институты принимались «студенты-кандидаты». Этот статус получали студенты после трехлетнего обучения, в продолжении которого осваивали «нужные курсы», необходимые для продолжения обучения «в котором-нибудь отделении». Поступив в педагогический институт, студенты-кандидаты продолжали здесь обучение еще в течение трех лет.

В Петербургском институте, как и в педагогических институтах при университетах, обучение шло три года. Однако здесь студенты не имели предварительной системной подготовки. Положение дел улучшилось в 1816 г., когда изменился статус учебного заведения, ставшего Главным педагогическим институтом. В нем был установлен шестилетний срок обучения [3].

Само преобразование института не было формальным переименованием. Его деятельность существенно расширялась. Вызвано это было ростом задач, связанных с необходимостью усиления централизованного руководства расширяющейся системой педагогического образования. Эта миссия в значительной своей части возлагалась на Главный педагогический институт. В соответствии с Высочайше утвержденным уставом назначение института теперь состояло «в образовании учителей, магистров, адъюнктов, профессоров для всех училищ в Империи...» [3, с. 1133]. Кроме того, институты, существовавшие при университетах, ставились в подчиненное положение по отношению к нему.

Главный педагогический институт заметно превзошел рамки учебного заведения, ориентированного на подготовку учителей. Неслучайно, просуществовав в этом статусе немногим более двух лет, он был преобразован в 1819 г. в Санкт-Петербургский университет. Однако в докладе министра просвещения отмечалось, что «образование учащих» оставалось его «существенным предметом» [8, с. 63].

С воцарением в 1825 г. Николая I внимание государства к вопросам образования усилилось. Заметно выросло количество учебных заведений. Это требовало выработки целенаправленной политики по развитию системы подготовки учительских кадров. Министр народного просвещения С.С. Уваров заявлял: «Увеличение числа заведений требовало новых преподавателей, усовершенствование и возвышение достоинства училищ требовало преподавателей лучших» [10, с. 27].

Поиск путей решение этой задачи привело к возрождению Главного педагогического института. Его преобразование в 1819 г. в университет вскоре показало, что без специализированного педагогического образовательного учреждения решить проблему учительских кадров было невозможно. Существовавшие при университетах педагогические институты с задачей подготовки преподавателей требуемого уровня квалификации и необходимого количества не справлялись.
30 сентября 1828 г. Николаем I был подписал указ об учреждении нового педагогического учебного заведения. В качестве обоснования этого решения констатировался «чувствуемый» во многих местах» «недостаток в надежных преподавателях». «Дабы отвратить происходящие от того неудобства, умножить число достойных наставников юношества и желающим готовить себя к сему почтенному званию открыть новые пути для приобретения нужных в оном сведений, - говорилось в указе, - Мы призвали за благо, сверх существующих уже для того студентских отделений при университетах, учредить в Санкт-Петербурге особое заведение под названием Главного педагогического института» $[6$, с. 852$]$.

В соответствии с уставом института [11] это закрытое учебное заведение учреждалось для «приготовления учителей и профессоров». В нем должны были обучаться 100 человек. При поступлении каждый «обязывался письменно» прослужить по окончании обучения не менее восьми лет в одном из учебных заведений.

Главный педагогический институт отличался высоким уровнем профессиональной подготовки будущих учителей. Его большую роль в формировании высококвалифицированных педагогических кадров подчеркивал Г.К. Шмид, приводя в своем исследовании слова одного из чиновников о качестве подготовки выпускников. Тот уверял: «Мои сослуживцы, воспитанники Главного педагогического института 2-го и 3-го выпусков, ....принимались за учительскую должность вовсе не новичками в искусстве преподавания, а это значит, что их дидактические опыты в институте не были для них бесполезны; познания же их в науках, для преподавания которых они назначались, своею обширностью и основательностью делали честь и студентам, и профессорам института» $[13$, с. 401$]$.

Главный педагогический институт, так же, как и педагогические институты при университетах, ориентированы были, прежде всего, на подготовку преподавателей гимназий и других средних учебных заведений. Однако С.С. Уваров выступил с инициативой о создании при институте так называемого «второго разряда», ориентированного на подготовку учителей для уездных училищ. Это было очень важно, поскольку, как писал министр, «издавна уже был ощутителен недостаток в заведении, предназначенном... для образования учителей начальных училищ» [10, с. 30].

«Второй разряд» был открыт в 1838 г. Он просуществовал до 1847 г. Сам Главный педагогический институт после этого действовал еще более 10 лет. Указ о его закрытии был издан в 1858 г. [4]. Педагогические институты при университетах были закрыты в 1860 г.

\section{Заключение}

Таковы были основные направления осуществлявшейся в первой половине XIX в. деятельности, направленной на создание и развитие в России системы педагогического образования. Следует отметить, что государственные структуры реально осознавали ее 
огромную значимость для успешного развития образования в стране. Главное место в кадровой политике занимали меры по подготовке преподавателей средних учебных заведений, в первую очередь гимназий. Определенные шаги предпринимались и в направлении профессионального обучения учителей для начальных учебных заведений. Во второй половине XIX в. обра- зовательная реформа Александра II потребует существенного расширения и качественного совершенствования мер по развитию педагогического образования. Важнейшее место займет деятельность, связанная с подготовкой учителей для системы начального народного образования.

\section{Список литературы}

1. Алешинцев И.А. История гимназического образования в России (XVIII и XIX век) / И.А. Алешинцев. СПб., 1912. - 346 с.

2. Галактионов И.А. Император Александр І и его царствование. Ч. 1-2 / И.А. Галактионов. - СПб., 18771879. $-211 \mathrm{c}$.

3. Новое образование Главного педагогического института с приложением штата оному. Высочайше утверждено 23 декабря 1816 года // Полное собрание законов Российской империи, с 1649 года. Собрание первое: в 45 т. Т. 33. - СПб., 1830. - С. 1133-1156.

4. О упразднении Главного педагогического института и об учреждении особых Педагогических курсов при университетах. Высочайше утвержденное Положение Главного правления училищ от 15 ноября 1858 года // Полное собрание законов Российской империи. Собрание второе: в 55 т. Т. 33. Отделение второе. - СПб., 1860. C. 389-390.

5. Об устройстве училищ. Именной указ, данный Сенату, от 24 января 1803 г. // Полное собрание законов Российской империи, с 1649 года. Собрание первое: в 45 т. Т. 27. - СПб., 1830. - С. 437-442.

6. Об учреждении в С.-Петербурге Главного педагогического института. Именной, данный Сенату, от 30 сентября 1828 года // Полное собрание законов Российской империи. Собрание второе: в 55 т. Т. 3. - СПб., 1830. C. 851-852.

7. Об учреждении Педагогического института в Санкт-Петербурге из бывшей прежде Учительской гимназии. Высочайше утвержденный доклад Министра народного просвещения от 16 апреля 1804 года // Полное собрание законов Российской империи, с 1649 года. Собрание первое: в 45 т. Т. 28. - СПб., 1830. - С. $270-281$.

8. Об учреждении Университета в Санкт-Петербурге. Высочайше утвержденный 8 февраля 1819 г. доклад Министра духовных дел и народного просвещения // Полное собрание законов Российской империи, с 1649 года. Собрание первое: в 45 т. Т. 36. - СПб., 1830. - С. 62-66.

9. Об учреждении учебных округов с назначением для каждого особых губерний. Именной указ, данный Сенату, от 24 января 1803 года // Полное собрание законов Российской империи, с 1649 года. Собрание первое: в 45 т. Т. 27. - СПб., 1830. - С. 442.

10. Уваров С.С. Десятилетие Министерства народного просвещения. 1833-1843. Записка, представленная Государю Императору Николаю Павловичу / С.С. Уваров. - СПб., 1864. - 161 с.

11. Устав Главного педагогического института. Высочайше утвержден 30 сентября 1828 года // Полное собрание законов Российской империи. Собрание второе. Т. 3. - СПб., 1830. - С. 852-869.

12. Устав учебных заведений, подведомых университетам. Высочайше утвержден 5 ноября 1804 г. // Полное собрание законов Российской империи, с 1649 года. Собрание первое: в 45 т. Т. 28. - СПб., 1830. - С. 626-647.

13. Шмид Г.К. История средних учебных заведений в России. Прил. к «Журналу Министерства народного просвещения» / Г.К. Шмид. - СПб., 1878. - 683 с.

\section{References}

1. Aleshintsev, I. A. (1912). History of gymnasium education in Russia. (XVIII and XIX century) (Russian Edition)., 346. Saint Petersburg.

2. Galaktionov, I. A. (1877-1879). Emperor Alexander I and his reign: Ch. 1-2., 211. Saint Petersburg.

3. (1830). Novoe obrazovanie Glavnogo pedagogicheskogo instituta s prilozheniem shtata onomu. Vysochaishe utverzhdeno 23 dekabria 1816 goda. Polnoe sobranie zakonov Rossiiskoi imperii, s 1649 goda. Sobranie pervoe, vol. 33, 1133-1156. Saint Petersburg.

4. (1860). O uprazdnenii Glavnogo pedagogicheskogo instituta i ob uchrezhdenii osobykh Pedagogicheskikh kursov pri universitetakh. Vysochaishe utverzhdennoe Polozhenie Glavnogo pravleniia uchilishch ot 15 noiabria 1858 goda. Polnoe sobranie zakonov Rossiiskoi imperii. Sobranie vtoroe, vol. 33, 389-390. Saint Petersburg.

5. (1830). Ob ustroistve uchilishch. Imennoi ukaz, dannyi Senatu, ot 24 ianvaria 1803 g. Polnoe sobranie zakonov Rossiiskoi imperii, s 1649 goda. Sobranie pervoe, vol. 27, 437-442. Saint Petersburg.

6. (1830). Ob uchrezhdenii v S.-Peterburge Glavnogo pedagogicheskogo instituta. Imennoi, dannyi Senatu, ot 30 sentiabria 1828 goda. Polnoe sobranie zakonov Rossiiskoi imperii. Sobranie vtoroe, vol. 3, 851-852. Saint Petersburg.

7. (1830). Ob uchrezhdenii Pedagogicheskogo instituta v Sankt-Peterburge iz byvshei prezhde Uchitel'skoi gimnazii. Vysochaishe utverzhdennyi doklad Ministra narodnogo prosveshcheniia ot 16 aprelia 1804 goda. Polnoe sobranie zakonov Rossiiskoi imperii, s 1649 goda. Sobranie pervoe, vol. 28, 270-281. Saint Petersburg. 
8. (1830). Ob uchrezhdenii Universiteta v Sankt-Peterburge. Vysochaishe utverzhdennyi 8 fevralia 1819 g. doklad Ministra dukhovnykh del i narodnogo prosveshcheniia. Polnoe sobranie zakonov Rossiiskoi imperii, s 1649 goda. Sobranie pervoe, vol. 36, 62-66. Saint Petersburg.

9. (1830). Ob uchrezhdenii uchebnykh okrugov s naznacheniem dlia kazhdogo osobykh gubernii. Imennoi ukaz, dannyi Senatu, ot 24 ianvaria 1803 goda. Polnoe sobranie zakonov Rossiiskoi imperii, s 1649 goda. Sobranie pervoe, vol. 27, 442. Saint Petersburg.

10. Uvarov, S. S. (1864). Desyatiletiye Ministerstva narodnogo prosveshcheniya [Decade of the Ministry of national education] 1833-1843. Zapiska, predstavlennaia Gosudariu Imperatoru Nikolaiu Pavlovichu., 161. Saint Petersburg.

11. (1830). Ustav Glavnogo pedagogicheskogo instituta. Vysochaishe utverzhden 30 sentiabria 1828 goda. Polnoe sobranie zakonov Rossiiskoi imperii. Sobranie vtoroe. Vol. 3, 852-869. Saint Petersburg.

12. (1830). Ustav uchebnykh zavedenii, podvedomykh universitetam. Vysochaishe utverzhden 5 noiabria 1804 g. Polnoe sobranie zakonov Rossiiskoi imperii, s 1649 goda. Sobranie pervoe, vol. 28. 626-647. Saint Petersburg.

13. Shmid, G. K. (1878). Istoriia srednikh uchebnykh zavedenii v Rossii [History of secondary schools in Russia]. Pril. k "Zhurnalu Ministerstva narodnogo prosveshcheniia"., 683. Saint Petersburg.

Информация об авторе

Поздняков Александр

Николаевич - д-р ист. наук, преподаватель Истринского профессионального колледжа филиала ГОУ ВО МО

«Государственный гуманитарнотехнологический университет», Истра, Российская Федерация.
Information about the author Aleksandr N. Pozdnyakov - doctor of historical sciences, teacher of the Is-tra Professional College - Branch of SEI of HE of Moscow Region "State University for the Humanities and Technology", Istra, Russian Federation.
Автор с̧инчен пе̌лтерни Поздняков Александр Николаевич - истори ӑслӑлӑхе̌н д-ре̌, ВМ АВ «Патшалӑх гуманитарипе технологи университече̌» ПВУ филиале̌н Истра професси колледже̌н преподавателе̌, Истра, Рас̧с̧ей Федерацийӗ. 